\title{
Quality of Life and Renal Functional Status In Patients With Cutaneous Ureterostomy and Ileal Conduit Urinary Diversion after Radical Cystectomy
}

Subrata Deb ${ }^{1}$, Md.Golam Mowla Chowdhury ${ }^{2}$ Mohammad Shafiqur Rahman ${ }^{3}$ Mohammad Salahuddin Faruque $^{4}$, Ashraful Islam ${ }^{5}$, Madhusudan Mondal ${ }^{6}$, Nirupom Mondal ${ }^{7}$, Md. Moktadir Hossain Mridha ${ }^{8}$

Received: 06 - 07 - 2020 Accepted: 05 - 09 - 2020 Conflicts of interest: None

Keywords: Gastropostatectomy, Pelvic exenteration, Ileal conduit, Cutaneous ureterostomy, EORTC, Quality of life, eGFR

\begin{abstract}
Introduction: Radical cystoprostetectomy in male patients and anterior pelvic exenteration in female patients coupled with en-block pelvic lymphadenectomy and urinary reconstruction or diversion remains the gold standard surgical approach to muscle invasive bladder cancer in the absence of metastatic disease. In Bangladesh, commonly performed urinary diversions are Cutaneous ureterostomy and Ileal conduit.

Types of urinary diversion have a great impact on different aspects of quality of life (QoL) as well as post-operative renal function.

Aims and Objectives: This study was designed to compare the Quality of Life and Renal Function in between Cutaneous ureterostomy and Ileal conduit urinary diversion after radical cystectomy.
\end{abstract}

Methodology: This was a hospital based Quasi Experimental study in which patients were selected by purposive sampling and, conducted from July, 2017 to September, 2018 in the department of Urology Bangabandhu Sheikh Mujib Medical University. This study was performed among the patients with muscle invasive bladder cancer treated by radical cystectomy with cutaneous ureterostomy or Ileal conduit fulfilling the exclusion and inclusion criteria. Total 34 patients were taken for the study, among them 17 for cutaneous ureterostomy and, 17 for Ileal Conduit Group.

Quality of Life was assessed through EORTC-QLQ-C30 questionnaire both pre and post operatively (3 months after operation). Renal function was assessed before and $1^{\text {st }}$ $P O D, 7^{\text {th }} P O D$, one month and three months after operation by measuring eGFR.

Result: Mean age of the patients was $59.00 \pm 8.60$ years and $53.35 \pm 8.43$ years in group$A$ (Cutaneous ureterostomy) and group-B (Ileal conduit) respectively. Three months after operation, overall QoL in all scales were improved in both group but, more improvements were noted in group- $B$ than group- $A$ which were statistically significant $(p<0.05)$. The mean pre-operative e GFR was significantly lower in group- $A$ than group- $B(p<0.001)$.

1. Resident Surgeon Urology, Sylhet MAG Osmani Medical College Hospital, Sylhet.

2. Professor of Uro-oncology, BSMMU, Dhaka

3. Associate Professor of Urology, BSMMU, Dhaka

4. Associate Professor of Urology, BSMMU, Dhaka

5. Assistant Registrar of Urology, Sylhet MAG Osmani Medical College Hospital, Sylhet.

6. Registrar, Department of Paediatric Urology, Dhaka Medical College Hospital, Dhaka.

7. Registrar, Urology, Khulna Medical College Hospital, Khuylna

8. Registrar, Shahid Mansur Ali Medical College, Sirajganj.

Correspondences: Dr. Subrata Deb, Residential Surgeon Urology, Sylhet MAG Osmani Medical College Hospital, Sylhet-3100, Bangladesh. E-mail: drsubrata27@gmail.com 
Three months after operation, statistically significant differences in eGFR, were observed within, and in between two groups ( $p<0.05$ ). Percentage of eGFR changed (renal function deterioration) were significantly more in group- $A$ than group $-B(p=0.001)$.

Conclusion: Quality of life, after radical cystectomy with ileal conduit is better than cutaneous ureterostomy and, post-operative renal function deterioration significantly less in ileal conduit group than cutaneous ureterostomy group. So, ileal conduit is an appropriate option of urinary diversion for the patient those who permit prolong operative procedure.

\section{Introduction}

Bladder cancer is the second most common cancer of the genitourinary tract. Radical cysto-prostetectomy in male patients and anterior pelvic exenteration in female patients coupled with disease. Urinary tract reconstruction following cystectomy is a challenge for the urologist (Afak et al,2009).

Radical cysto-prostetectomy in male patients and anterior pelvic exenteration in female patients coupled with en-block pelvic lymphadenectomy and urinary tract reconstruction or diversion remains the gold standard surgical treatment to muscle invasive bladder cancer in the absence of metastatic disease. There are various methods of urinary diversion, including continent and incontinent diversion. Cutaneous Ureterostomy and Ileal Conduit are commonly performed method of urinary diversion(Mucciardi et al, 2015).Factors that are considered to choose a urinary diversion include patients age, body habits, manual dexterity, physical and mental status, renal function, prognosis of primary disease, existing bowel pathology, prior radiation or chemotherapy, the presence of medical disease, the expectation, preferences, fears of the patients and the experience and preference of surgeon (Afak et al, 2009).

Types of urinary diversion have a great impact on different aspects of quality of life (QoL), including micturition status, physical, sexual, and psychosocial functioning, day life activities and distress related to body image (Gerharz et al,2005).

In addition, the concept of quality of life (QoL) differs significantly between cultures, countries, and races, surgical expertise and available facility. Quality of life (QoL) is more satisfactory in continent urinary diversion than incontinent diversion. But there were limited studies available in QoL and renal function in high risk patients with incontinent diversion (Asgari et al,2013).

In Bangladesh, frequently performed urinary diversions were cutaneous ureterostomy and ileal conduit as because of delayed presentation of patients.

\section{Methodology:}

Those patients with evidence of muscle invasive bladder cancer had been treated by Rradical cystectomy with Cutaneous ureterostomy or Ileal conduit urinary diversion, and who were interested to join the research work, were included in this study . Purposive sampling was done. Total 34 patients were included, among them, 17 in Cutaneous ureterostmy Group, and 17 in Ileal conduit Group. All the patients were operated in BSMMU. Total procedures included evaluation of patient; Pre-operative counseling and preparation, pre-operative assessment of Quality of Life (QoL), surgical intervention, post-operative care and follow up. The assessment of the QoL related to health was performed before and 3 months after surgery in every patient using the questionnaire "European Organization for Research and Treatment of Cancer Quality of Life questionnaire-C30" (EORTC QLQ-C30).

The EORTC QLQ-C30 questionnaire is an instrument validated for quality of life assessment in oncological patients. The most recent version, 3.0, was used in this study. Renal function was assessed by measuring eGFR before operation, on $1^{\text {st }}$ and $7^{\text {th }}$ POD, and again 3 months after operation.

\section{Result:}

Table I: Patients characteristics in both group $(n=34)$

\begin{tabular}{lccc}
\hline & \multicolumn{2}{c}{ Group } & p- \\
\cline { 2 - 3 } & $\begin{array}{c}\text { Group A } \\
\text { (cutaneous } \\
\text { ureterostom) }\end{array}$ & $\begin{array}{c}\text { Group B } \\
\text { (Ileal } \\
\text { conduit) }\end{array}$ & \\
\hline Sex & $16(94.1)$ & $15(88.2)$ & $1.000^{*}$ \\
Male & $1(5.9)$ & $2(11.8)$ & \\
Female & $59.00 \pm 8.60$ & $53.35 \pm 8.43$ & $0.062^{* *}$ \\
Age (years) & $43-73$ & $35-71$ & \\
& & & \\
\hline
\end{tabular}

*Fisher's Exact test and, ${ }^{* *}$ unpaired $\mathrm{t}$ test was done to measure the level of significance 
Quality of Life and Renal Functional Status In Patients With Cutaneous Ureterostomy and Ileal Conduit Urinary Diversion

Table II: Pre-operative co-morbidities of the patients in both group $(n=34)$

\begin{tabular}{lccc}
\hline & \multicolumn{2}{c}{ Group } & p-value \\
\cline { 2 - 3 } & Group A & Group B & \\
\hline DM & (Cutaneous ureterostomy) & $1(5.9 \%)$ & 0.601 \\
HTN & $3(17.6 \%)$ & $4(23.6 \%)$ & 0.125 \\
COPD & $5(29.5 \%)$ & $1(5.9 \%)$ & 0.601 \\
\hline
\end{tabular}

Fisher's Exact test was done to measure the level of significance

Table III: Comparison of QoL in the form of functional scale before and 3 months after operation in group A (Cutateous ureteroatomy group) $(n=17)$

\begin{tabular}{lccc}
\hline & Before operation & After operation & p-value \\
\hline Physical functioning & $31.10 \pm 10.15$ & $49.41 \pm 14.54$ & $<0.001$ \\
Role functioning & $29.55 \pm 10.11$ & $44.12 \pm 15.52$ & $<0.001$ \\
Emotional functioning & $26.47 \pm 14.80$ & $37.25 \pm 11.07$ & 0.035 \\
Cognitive functioning & $29.47 \pm 10.31$ & $45.10 \pm 12.86$ & 0.002 \\
Social functioning & $27.45 \pm 11.70$ & $43.14 \pm 13.25$ & 0.003 \\
QoL & $28.51 \pm 8.57$ & $43.63 \pm 6.93$ & $<0.001$ \\
\hline
\end{tabular}

Table IV: Comparison of QoL in the form of functional scale before and 3 months after operation in group B (Ileal conduit group) $(\mathrm{n}=17)$

\begin{tabular}{lccc}
\hline & Before operation & After operation & p-value \\
\hline Physical functioning & $34.90 \pm 8.34$ & $74.51 \pm 11.84$ & $<0.001$ \\
Role functioning & $33.33 \pm 14.43$ & $73.53 \pm 15.66$ & $<0.001$ \\
Emotional functioning & $28.92 \pm 8.90$ & $67.16 \pm 13.97$ & $<0.001$ \\
Cognitive functioning & $38.24 \pm 11.43$ & $85.29 \pm 11.61$ & $<0.001$ \\
Social functioning & $29.41 \pm 9.37$ & $72.55 \pm 14.36$ & $<0.001$ \\
QoL & $32.84 \pm 7.49$ & $73.53 \pm 19.15$ & $<0.001$ \\
\hline
\end{tabular}

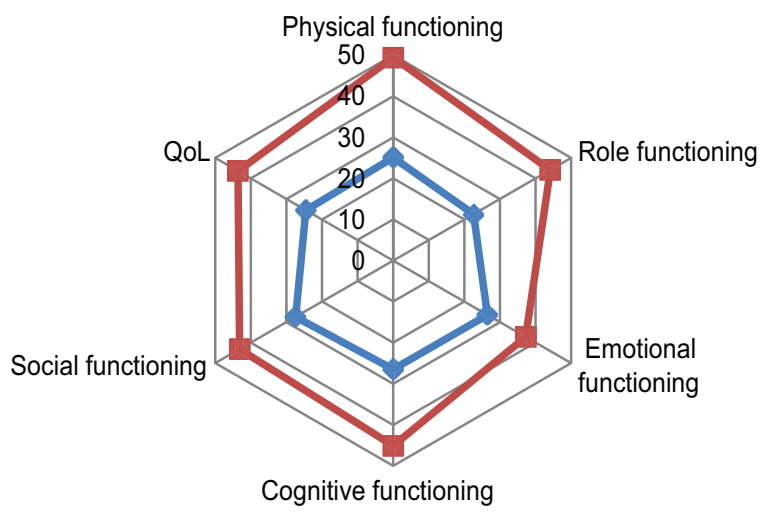

$\longrightarrow$ Prior to surgery $\quad-3$ months after surgery

Fig.-1: (Radar graph): QoL and functional scales before and after surgery in group A (Cutaneous Ureterostomy group)

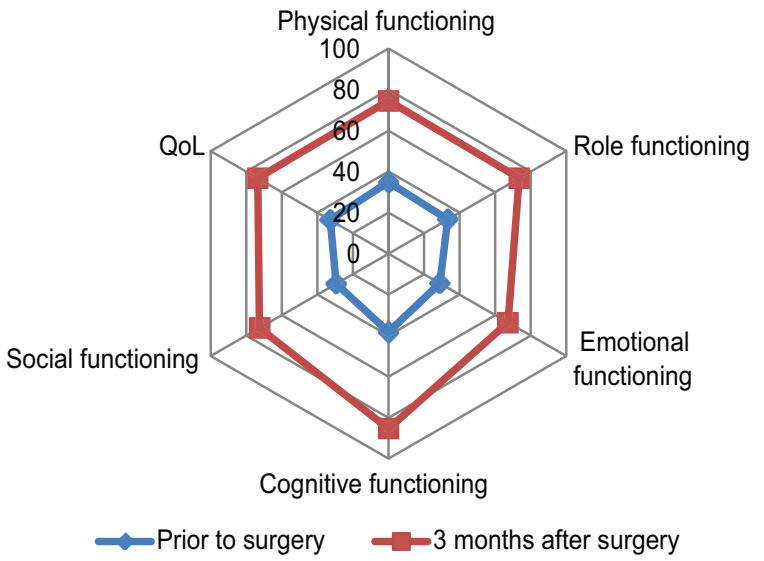

Fig.-2: (Radar graph): QoL and functional scales before and after surgery in group B (Ileal conduit group). 
Table V: Comparison of Quality of Life in the form of Functional scale and overall QoL, 3 months after operation between groups $(n=34)$

\begin{tabular}{lccc}
\hline & \multicolumn{2}{c}{ Group } & p-value \\
\cline { 2 - 3 } & $\begin{array}{c}\text { Group A } \\
\text { (Cutaneous ureterostomy) }\end{array}$ & $\begin{array}{c}\text { Group B } \\
\text { (Ileal conduit) }\end{array}$ & \\
\hline Physical functioning & $49.41 \pm 14.54$ & $74.51 \pm 11.84$ & $<0.001$ \\
Role functioning & $44.12 \pm 15.52$ & $73.53 \pm 15.66$ & $<0.001$ \\
Emotional functioning & $37.25 \pm 11.07$ & $67.16 \pm 13.97$ & $<0.001$ \\
Cognitive functioning & $45.10 \pm 12.86$ & $85.29 \pm 11.61$ & $<0.001$ \\
Social functioning & $43.14 \pm 13.25$ & $72.55 \pm 14.36$ & $<0.001$ \\
QoL & $43.63 \pm 6.93$ & $73.53 \pm 19.15$ & $<0.001$ \\
\hline
\end{tabular}

Unpaired $t$ test was done to measure the level of significance

Table VI: Comparison of QoL in the form of symptom scale before and after operation in group A (Cutaneous ureterostomy group) $(n=17)$

\begin{tabular}{lccc}
\hline & Before operation & After operation & p-value \\
\hline Fatigue & $79.08 \pm 11.71$ & $62.75 \pm 11.75$ & $<0.001$ \\
Nausea and vomiting & $85.29 \pm 13.02$ & $58.82 \pm 11.96$ & $<0.001$ \\
Pain & $77.45 \pm 10.11$ & $53.92 \pm 9.37$ & $<0.001$ \\
Dyspnea & $80.39 \pm 16.91$ & $52.94 \pm 16.91$ & $<0.001$ \\
Insomnia & $82.35 \pm 20.81$ & $62.75 \pm 16.17$ & 0.008 \\
Appetite loss & $94.12 \pm 13.10$ & $64.71 \pm 18.52$ & $<0.001$ \\
Constipation & $52.94 \pm 37.38$ & $49.02 \pm 26.66$ & 0.543 \\
Diarrhoea & $76.47 \pm 28.30$ & $60.78 \pm 21.20$ & 0.056 \\
Financial difficulties & $60.78 \pm 21.20$ & $50.98 \pm 20.81$ & 0.264 \\
\hline
\end{tabular}

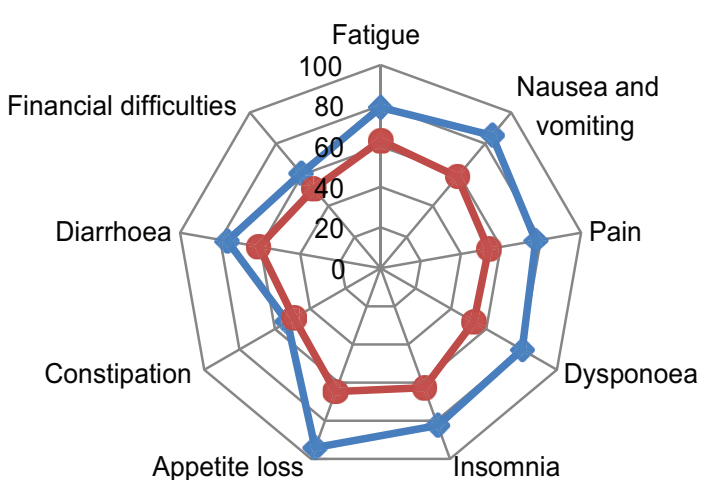

$\longrightarrow$ Prior to surgery $\quad-3$ months after surgery

Fig.-3 (Radar graph): Symptom scales before and after surgery in group A (Cutaneous Ureterostomy group).

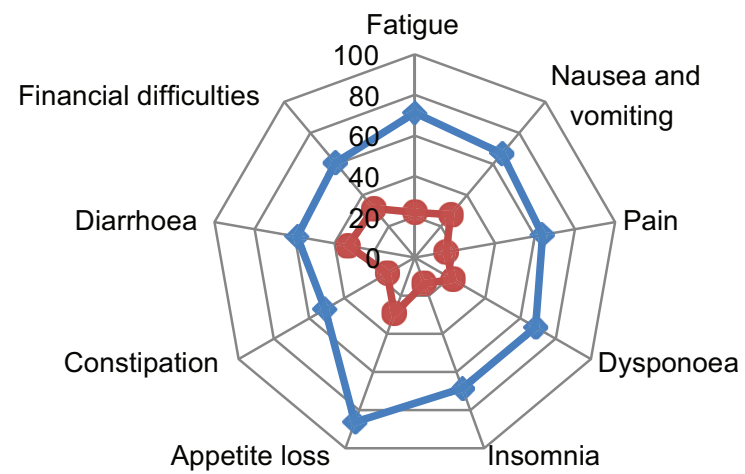

$\longrightarrow$ Prior to surgery $\quad-3$ months after surgery

Fig.-4 (Radar graph): Symptom scales before and after surgery in group B (Ileal conduit Group). 
Quality of Life and Renal Functional Status In Patients With Cutaneous Ureterostomy and Ileal Conduit Urinary Diversion

Table VII: Comparison of QoL in the form of symptom scale before and after operation in group B (Ileal conduit group) $(n=17)$

\begin{tabular}{lccc}
\hline & Before operation & After operation & p-value \\
\hline Fatigue & $71.24 \pm 11.15$ & $22.22 \pm 14.16$ & $<0.001$ \\
Nausea and vomiting & $66.67 \pm 13.18$ & $27.45 \pm 19.49$ & $<0.001$ \\
Pain & $63.73 \pm 12.13$ & $15.69 \pm 13.78$ & $<0.001$ \\
Dyspnea & $68.63 \pm 14.29$ & $21.57 \pm 20.21$ & $<0.001$ \\
Insomnia & $68.63 \pm 14.29$ & $13.73 \pm 20.61$ & $<0.001$ \\
Appetite loss & $86.27 \pm 16.91$ & $29.41 \pm 23.22$ & $<0.001$ \\
Constipation & $50.98 \pm 37.49$ & $15.69 \pm 20.81$ & $<0.001$ \\
Diarrhoea & $58.82 \pm 27.71$ & $33.33 \pm 23.57$ & 0.014 \\
Financial difficulties & $60.78 \pm 24.25$ & $31.37 \pm 24.92$ & $<0.001$ \\
\hline
\end{tabular}

Table VIII: Comparison of Quality of in the form of symptoms scale 3 months after Operation between groups ( $n=34)$

\begin{tabular}{lccc}
\hline & \multicolumn{2}{c}{ Group } & p-value \\
\cline { 2 - 3 } & $\begin{array}{c}\text { Group A } \\
\text { (Cutaneous ureterostomy) }\end{array}$ & $\begin{array}{c}\text { Group B } \\
\text { (Ileal conduit) }\end{array}$ & \\
\hline Fatigue & $62.75 \pm 11.75$ & $22.22 \pm 14.16$ & $<0.001$ \\
Nausea and vomiting & $58.82 \pm 11.96$ & $27.45 \pm 19.49$ & $<0.001$ \\
Pain & $53.92 \pm 9.37$ & $15.69 \pm 13.78$ & $<0.001$ \\
Dyspnoea & $52.94 \pm 16.91$ & $21.57 \pm 20.21$ & $<0.001$ \\
Insomnia & $62.75 \pm 16.17$ & $13.73 \pm 20.61$ & $<0.001$ \\
Appetite loss & $64.71 \pm 18.52$ & $29.41 \pm 23.22$ & $<0.001$ \\
Constipation & $49.02 \pm 26.66$ & $15.69 \pm 20.81$ & $<0.001$ \\
Diarrhoea & $60.78 \pm 21.20$ & $33.33 \pm 23.57$ & 0.001 \\
Financial difficulties & $50.98 \pm 20.81$ & $31.37 \pm 24.92$ & 0.018 \\
\hline
\end{tabular}

Unpaired $\mathrm{t}$ test was done to measure the level of significance

Table IX: $e$ GFR level before and after operation $(n=34)$

\begin{tabular}{|c|c|c|c|}
\hline & \multicolumn{2}{|c|}{ Group } & \multirow[t]{3}{*}{ p-value } \\
\hline & Group A & Group B & \\
\hline & (Cutaneous ureterostomy) & (Ileal conduit) & \\
\hline Before operation & $54.65 \pm 9.19$ & $64.94 \pm 5.79$ & $<0.001$ \\
\hline \multicolumn{4}{|l|}{ After operation } \\
\hline At $1^{\text {st }}$ POD & $52.82 \pm 11.70$ & $64.88 \pm 5.80$ & 0.001 \\
\hline At $7^{\text {th }}$ POD & $53.82 \pm 9.70$ & $64.94 \pm 5.79$ & $<0.001$ \\
\hline After 3 months of POD & $53.41 \pm 9.59$ & $64.53 \pm 5.69$ & $<0.001$ \\
\hline$\%$ change in eGFR & $2.52 \pm 2.08$ & $0.62 \pm 0.77$ & 0.001 \\
\hline P value (before op vs $3 n$ & after op) $<0.001$ & 0.004 & \\
\hline
\end{tabular}

Unpaired $t$ test was done between groups and paired $t$ test was done within group 
Table IX shows the level of eGFR before and after operation in both group of patients. Before operation mean $( \pm S D)$ eGFR was $54.65 \pm 9.19$ and $64.94 \pm 5.79$ in Group-A and Group-B respectively, and there was a statistically significant differences in both groups $(p<0.001)$. After operation eGFR was gradually decreases in both groups. 3 months after operation mean $( \pm$ SD) eGFR was $53.41 \pm 9.59$ and $64.53 \pm 5.69$ in Group-A and Group-B respectively. Percentage (\%) change of Mean $( \pm$ SD) eGFR values within Groups , 3 months after operation were $2.52 \pm 2.08$ and $0.62 \pm$ 0.77 in Group-A and Group-B respectively. There were statistically significant differences in eGFR status from pre-operative period to 3 months after operation between and within the groups $(\mathrm{p}=<0.001,<0.001$, $<0.004)$.

\section{Discussion:}

After radical cystectomy urinary diversion is mandatory. The principal goal in selection of urinary diversion method is local cancer control; however, potential for short-term and long-term complications, the best Quality of Life (QoL) and post -operative renal function are also important factors. In Bangladesh usually cutaneous ureterostomy and ileal conduit are performed as a urinary diversion. In this study age of the patients ranged from 43 years to 73 years in Group$A$ and 35 to 71 years in Group-B. The mean age of Group-A was $59.00 \pm 8.60$ years and , Group-B was $53.35 \pm 8.60$ years which was statistically indifferent $(p=0.062)$. The mean age of the patients of this study was not comparable with the study done in developed worlds (Mucciardi et al 2015, Huang et al 2015). Mean age of the present study was lower than developed world and, it's may be due to higher life expectancy in the developed world. Saika et al (2007) stated that age is not a factor in the choice of the urinary diversion method, and considered that reconstruction with neobladder after radical cystectomy for bladder cancer is the method of choice even in the elderly patients if the baseline condition of the patients allow it. Siddiqui and Izawa (2015) concluded that ileal conduit poses the least metabolic challenges making it the diversion of choice for many elderly patients and those with reduced renal function.

In this study it was observed that male predominant in both groups, $94.1 \%$ in Group-A and $88.2 \%$ in Group$B$ due to male predominance of the disease. Similar studies done by Osawa et al (2013), Mucciardi et al (2015), and Huang et al (2015) showed male predominance of the bladder cancer.
The male predominance in Bangladesh may be due to presence of increased risk factors in male (cigarette smoking, job profession in various chemical industries and exposure to toxin). In this study female patients were less in number because of less hospital bed number in female ward in Bangabandhu Sheikh Mujib Medical University.

In this study frequent co-morbidities were HTN, DM and COPD. Apparently more co-morbidities were observed in Group-A patients (DM-17.6\%, HTN-29.5\%, COPD-17.6\%) than Group-B patients (DM-5.9\%, HTN$23.6 \%$, COPD- $5.9 \%)$, but there were no statistically significant differences in both groups.

In this study, Quality of Life (QoL) in the form of functional scale, symptoms scale and overall QoL were assessed before and 3 months after operation in both groups and, result showed that a statistically significant improvement in almost all the parameters observed 3 months after surgery within and between the Groups. More improvement (increased functional scores and decreased symptoms scores) was observed in GroupB (Ileal conduit group) than Group-A (Cutaneous ureterostomy group), which was statistically significant $(\mathrm{p}<0.001)$. Mucciardi et al (2015) observed similar result 6 months after operation in their study. Siddiqui and Izawa (2015) observed clinically significant improvement in QoL after radical cystectomy with Ileal conduit.

Anderson et al (2012) used a condition specific health -related quality of life (HRQOL) survey known as Functional Assessment of cancer therapy -Vanderbilt Cystectomy index (FACT-VCI) to assess QoL after radical cystectomy. This study reported a clinically significant improvement in QoL after Ileal Conduit.

Some authors state that considerations about the current quality of life are of great importance to assess the results of a surgical intervention and that they are one of the main reasons at the time of choosing the urinary diversion after a radical cystectomy ( Lee et al, 2014).

Despite the fact that urinary problems and sexual dysfunction are common to all methods of urinary diversion ( Saika et al 2007), the QoL related to health seems to be relatively good in elderly patients after radical cystectomy for bladder cancer, regardless of the urinary diversion method chosen.

One major problem in comparing the results of different studies is a lack of universal standard 
questionnaire for the purpose of addressing different domains of QoL in cystectomized patients. The problems include lack of standard definition of QoL, and cultural differences in judgment and expression of both physical and emotional health. In addition, sample size, study design and characteristics of the population analyzed are also confounding factors. The potential effects of sociocultural settings on the concept of QoL have also been raised. The cultural pattern of the studied population can affect the study results. Patients education, describing the pros and cons of the different urinary diversion methods, and active participation of the patient in selecting treatment methods (shared decision making) appear to be some of the key points to post-operative QoL and satisfaction.

One of the major limitations of this study was lack of addressing the sexual life of the patients, which is an important item of QoL. Asgari et al (2013) stated that erectile dysfunction occurred irrespective of type of urinary diversion and there were no statistically significant differences in different type of diversions. They also concluded that the rate of satisfaction from sexual life in different type of diversions did not reach in statistically significant differences.

In this study, in pre-operative period, mean eGFR was less in Group-A ( $54.65 \mathrm{ml} / \mathrm{min}$ ) than Group-B ( $64.94 \mathrm{ml} / \mathrm{min}$ ) and It's may be due to more comorbidities ( DM, HTN, pre-operative HDUN) in Group-A and, the difference in both groups was statistically significant $(\mathrm{p}<0.001)$. Osawa et al (2012) observed comparable result of pre-operative eGFR in their study $(p=0.01)$.

The time dependent changes of mean eGFR status at $1^{\text {st }}$ POD, $7^{\text {th }}$ POD and, after 3 months of operation were statistically significant between two groups $(p<0.05)$. Percentage of eGFR changes (reduction) 3 months after operation from base line were $2.52 \%$ in Group-A and $0.62 \%$ in Group-B and, the changes (reduction) were statistically significant within the groups, and in between two groups. Although significant but comparatively less deterioration of eGFR was observed in Group-B (Ileal conduit group) than Group-A (Cutaneous ureterostomy group).

Current result differ from, the study by Osawa et al (2013) in which, they showed that there was no significant difference in renal deterioration among the different types of diversions. Hatakeyama et al (2016) concluded that types of urinary diversion had no significant effect on renal function decline. It was also different from the current study.

In the present study, in Group-B (Ileal Conduit) mean eGFR reduction $(0.41 \mathrm{ml} / \mathrm{min} / 1.73 \mathrm{~m} 2)$ was less than the define value $(>1 \mathrm{ml} / \mathrm{min} / 1.73 \mathrm{~m} 2)$, but in GroupA ( Cutaneous Ureterostomy) mean eGFR reduction $\left(1.24 \mathrm{ml} / \mathrm{min} / 1.73 \mathrm{~m}^{2}\right)$ was more than the define value of deterioration and, the difference was statistically significant, although study period was short.

At the end of the discussion, the present study suggested that post- operative Quality of life and renal function were better in ileal conduit group (Group-B) than cutaneous ureterostomy group ( Group-A) following radical cystectomy for muscle invasive bladder cancer.

\section{Conclusion:}

Quality of life, after Radical Cystectomy with Ileal conduit is superior in all aspect than Cutaneous ureterostomy and, post-operative Renal function reduction rate is less in Ileal conduit Group than Cutaneous ureterostomy Group, Ileal conduit is an appropriate option of urinary diversion for the patients who have base line physiological parameters that permit prolong operative procedure.

Ethical issues: The protocol was submitted to Institutional Review Board (IRB) of Bangabandhu Sheikh Mujib Medical University for their approval, and their permission was taken prior to the Research work.

Informed written consent was taken from each of the patient after proper counseling.

\section{References}

1. Afak YS, Wazir BS, Hamid A, Wani MS, Aziz R (2009), Comparative study of Various Forms of Urinary Diversion after Radical Cystectomy in Muscle Invasive Carcinoma of Urinary Bladder . Int J Health Sci (Qassim);3,1:3-11.

2. Amni E, Djaladat H (2015) Long Term complications of urinary diversion, Curr Opin Urol,25:6,570-77.

3. Anderson $\mathrm{CB}$, Feurer ID, Large MC, Steinberg GD, Barocas DA, Cookson MS et al (2012) Psychometric characteristics of a condition specific, health related quality of life survey :the FACT-Vanderbilt Cystectomy Index. Urology 80:77-83. 
4. Asgari M, Safarinejad M, Shakhssalim N, Soleimani M, Shahabi A, Amini E (2013) Quality of life after radical cystectomy for bladder cancer in men with an ileal conduit or continent urinary diversion: A comparative study. Urology Annals;5,3:190-196.

5. Aziz A, May M, Burger M, Palissar RJ, Trinh QD, Fritsche HM et al (2011) Prediction of 90-day mortality after radical cystectomy for bladder cancer in a prospective European multicenter cohort .Eur Urol 66:156-163.

6. Botteman MF, Pashos CL, Redaelli A, Laskin B, Hauser R(2003) The health economics of bladder cancer: a comprehensive review of the published literature Pharmacoeconomics,21, 1315-1330.

7. Cohen E, Nardi Y, Kruise I et al (2014) A longitudinal assessment of the natural rate of decline in renal function with age. J Nephrol;27:635-41.

8. David P, Wood JR, (2016), Tumors of the Bladder. In: Wein AJ, Kavous LR, Patrin AW, Peters CA (eds). Campbell-Walsh Urology , $11^{\text {th }}$ Edition, Vol3, Elsevier, Philadelphia, p.2184-2204.

9. De Nunzio C, Cindolo L, Leonardo C, Antonelli A, Ceruti C, Franco G et al (2013), Analysis of radical cystectomy and urinary diversion complications with the Clavien classification system in an Italian real life cohort. Eur J Surg Oncol;39:792-798 .

10. Falser P,Ribstein J, du Cailar G ( 2005) Determinants of cardio-renal damage progression in normotensive and never treated hypertensive subjects. Kidney Int 67:1974-1979.

11. Fritsche HM, Burger M, Ganzer R, Otto W, Denzinger S, Wieland WF (2008) Impact of comorbidity on peri-operative mortality after radical cystectomy. Aktuel Urol; 39:225-8.

12. Gondo T, Ohno $\mathrm{Y}$, Nakashima J, Hashimoto T, Nakagami Y, Tachibana M (2017) Pre-operative determinant of early post -operative renal function following radical cystectomy and intestinal urinary diversion, International Urology and Nephrology; 49:2;233-38.

13. Hatakeyama S, Koie T, Narita T, Hosogoe S, Yamamto H, Tobisawa Y, Yoneyama T, (2016) Renal function Outcomes and Risk Factors for stage 3B chronic Kidney Disease After Urinary Diversion in Patient with Muscle Invasive Bladder Cancer. Journal of Urology,10,1371.

14. Hollenbeck BK, Miller DC, Taub D, Dunn RL, Underwood W, Montie JE, and Wei JT, 2004. Aggressive treatment for bladder cancer is associated with improved overall survival among patients 80 years old or older. Urology, 64(2):292297.

15. Huang JH, Lu JY, Yao XD, Peng B, Wang GC, Zheng JH (2015) Comparison of two kinds of cutaneous ureterostomy using in radical cystectomy. Int J Clin Exp Med,8(8):14371- 14375.

16. Jin XD, Roethlisberger S, Burkhard FC et al ( 2012) long term renal function after urinary diversion by ileal conduit or orthotopic ileal bladder substitution . Eur Urol 61:491-497.

17. Karl A, Buchner A, Becker A, Staehler M, Seitz M, Khoder W et al (2014) A new concept for patient recovery after surgery for patients undergoing radical cystectomy for bladder cancer : result of prospective randomized study. J Urol 19(2):335-340.

18. Konety BR, Carroll PR, (2013) Urothelial Carcinoma:Cancer of the bladder,ureter,and renal pelvis. In: McAninch JW, Lue TF (eds) Smith \& Tanagho's General Urogy. $18^{\text {th }}$ Edition. Mc Grow Hill, New York: p 310-29.

19. Lee RK, Abol-Enein H, Artibani W, Bochner B, Dalbagni G, Daneshmand S et al (2014), Urinary Diversion after Radical Cystectomy for bladder cancer : options, patient selection, and outcomes. BJU Int ; 113:11-23.

20. Leveridge MJ, Siemens DR, Mackillop WJ, Peng Y, Tannock IF, Berman DM, Booth CM (2015) Radical Cystectomy and adjuvant chemotherapy for bladder cancer in elderly ; a population based study . Urology 85:791-798.

21. Makino K, Nakagawa T, Kanatani A, Kawai T, Taguchi S, Matsumoto A (2016) Biphasic decline in renal function after radical cystectomy with urinary diversion. Int J Clin Oncol,22(2):359-365.

22. Mucciardi G, Macchione L, Gali A (2015) Quality of life and overall survival in High Risk Patients After Radical Cystectomy, Cir Esp. 2015 Jun-Jul; 93(6):368-74. 
23. Nazmy M, Yuh B, Kawachi M, Lau CS, Linhean J, Ruel NH et al (2013) Early and late complications of robot assisted Radical cystectomy : a standardized analysis by urinary diversion type. J Urol 191:681-687.

24. Nishikawa M, Miyake H, Yamshita M, Inou T, Fujisawa M (2014) Long-term changes in renal function outcomes following radical cystectomy and urinary diversion. Int J Clin Oncol 19(6):11051111.

25. Novotny V, Hakenberg OW, Wiessner D, Heberling U, Litz RJ, Oehlschlaeger S and Wirth MP(2007) Perioperative complication of radical cystectomy in a contemporary series. European Urology, 51 (2): 397-402.

26. Osawa T, Shinohara N, Maruyama s, Oba K, Abe T, Maru S et al (2013) Long term Renal Function Outcomes in Bladder Cancer After Radical cystectomy. Urological oncology,10,1,784-9.

27. Park J, Ahn H (2011) Radical cystectomy and orthotropic bladder substitution using ileum. Korean J Urol,52,233-40 .

28. Rouanne M, Perreaud A, Letang N, Yonneau L, Neuzillet Y,Heve JM, Botto H, Lebert T,2015, Trends in Renal Function After Radical Cystectomy and Ileal Conduit Diversion: New Insights Regarding Estimated Glomerular Filtration Rate Variations. Clinical Genitourinary Cancer,13(3):e139-44.
29. Saika T, Arata R, Tsushima T, Nasu Y, Suyama B, Takeda K et al ( 2007) Health related Quality of life after radical cystectomy for bladder cancer in the elderly patients with an ileal conduit, ureterocutaneostomy, or orthotopic urinary reservoir : a comparative questionnaire survey . Acta Med Okayama.61:199-203.

30. Schiffman J, Gandglia G, Larcher A, Sun M, Tian Z, Shariat SF et al (2014) Contemporary 90 -day mortality rate after radical cystectomy in the elderly . Eur J Surg Oncol 40:1738-1745.

31. Shabsigh A, Korests R, Vora KC, Brooks CM, Cronin AM, Savage C et al, (2009) Defining early morbidity of radical cystectomy for patients with bladder cancer using a standardized reporting methodology. Eur Urol 55:164-174.

32. Shariat SF, Milowksy M, Dollar MJ,( 2009) Bladder Cancer in the Elderly .Uro Oncol 27:653667.

33. Siddiqui KM, Izawa JI (2015) Ileal Conduit: Standard Urinary Diversion for elderly patients undergoing radical cystectomy. Word J. Urol, 34:19-24.

34. Skinner EC, Daneshmand S (2016) Orthotopic urinary diversion; . In: Wein AJ, Kavous LR, Patrin AW, Peters CA (eds). Campbell-Walsh Urology , $11^{\text {th }}$ Edition, Vol-3, Elsevier, Philadelphia, p.2344-68. 